\title{
Effect of Growth Regulators on Callus Culture and Regeneration of Morus alba L.
}

\author{
Vandana Dubey ${ }^{1 \star}$, Dr. Shagufta Khan ${ }^{3}$, Dr. Kunwar Wajahat Shah ${ }^{2}$, Dr. R. K. Raghuwanshi ${ }^{1}$ \\ ${ }^{1}$ Government Narmada Mahavidyalaya, Hoshangabad-461001, M.P., India \\ ${ }^{2}$ Government PG College, Pipariya-461775, M.P., India \\ ${ }^{3}$ GrowTips Biotech, Saket Nagar, Bhopal (MP)- 462024, India
}

\author{
Article Information \\ Received 5 May 2020 \\ Received in revised form 28 Aug 2020 \\ Accepted 29 August 2020 \\ Keywords: \\ Auxin, \\ Cytokinin, \\ Callus, \\ Mature explants, \\ Morus alba \\ Corresponding Author: \\ E-mail : dubeyvandana143@gmail.com \\ Mob.: $x x x x x x x x x$ \\ DOI: $10.20510 /$ ukjpb/8/i4/1599394008
}

\begin{abstract}
Plantlets of the Morus alba L. were produced from callus initiated from leaf, internodal segments, and petiole explants on MS basal medium fortified with auxins and cytokinins like 2, 4-D, NAA and 6-benzylaminopurine (BAP). Callogenesis was dependent on the nature of explants used, and growth regulators supplemented in the medium. Leaves were the best explant used for callus induction. Maximum callus was obtained on MS medium containing a combination of $1.0 \mathrm{mg} / 12,4-\mathrm{D}$ and $0.5 \mathrm{mg} / \mathrm{I}(80 \%)$. The regeneration of shoots from callus was seen on MS medium supplemented with $1.0 \mathrm{mg} / \mathrm{l} \mathrm{BAP}$ and 0.5 NAA. Presence of NAA in the medium also improved the long term organogenic potential of the callus. Regenerated shoots produced best roots on Murashige \& Skoog (MS) half concentration medium containing $20 \mathrm{mg} / \mathrm{l}$.
\end{abstract}

\section{Introduction}

Morus alba L. is an important and valuable tree for the sericulture industry, as it is the source of food for silkworm ${ }^{1}$. In India, there are many varieties are cultivated for commercial purposes in Jammu and Kashmir, West Bengal, Karnataka and Tamil $\mathrm{Nadu}^{2,3}$. Methods of conventional vegetative propagation through grafting is not economically viable for these varieties because it involves skilled manpower, expensive nursery facilities and a minimum time period of 4-5 years to obtain plants ready for harvest ${ }^{4}$. Propagation of plants through cuttings is also not viable for these varieties due to their poor rooting ability.

Tissue culture propagation can be a viable alternative method for rapid multiplication of the elite varieties of mulberries plant for large production and cultivation purpose. The successful regeneration of in vitro plants has been achieved in several mulberry species by axillary shoot proliferation and organogenesis from callus cultures.

These studies have discovered that regeneration ability in Morus alba is greatly dependent on the supplemented growth regulators and plant part used for callus induction ${ }^{5-8}$. These factors have been investigated separately without examining their interaction and the regeneration potential of these protocols was very low and inconsistent and Mulberry (Morus) is an invaluable tree for the sericulture industry, as it is the only source of food for silkworm¹.

Propagation of plants through cuttings is also not viable for these varieties due to their poor rooting ability. An attempt to induce rooting in stem cuttings of these varieties by auxin application has not yielded encouraging results ${ }^{9}$. Tissue culture propagation can be a viable alternative for rapid multiplication of the mulberries. The successful regeneration of plants in vitro has been achieved in several mulberry species by axillary shoot proliferation and organogenesis from callus cultures ${ }^{1}$.

These studies have revealed that regeneration ability in Morus alba is greatly dependent on the growth regulator combinations, explant type and the mulberry genotype. These factors have been investigated separately without examining their interaction and the regeneration potential of these protocols was very low and inconsistent.

Furthermore, a major problem with these studies was that immature tissues have been employed as explants during the standardization of regeneration systems. This paper reveals the studies on the role of growth regulators, types of explants obtained from mature and in vitro culture plants from callus 
mediated organogenesis and evaluates the long term regeneration potential of the callus ${ }^{10,11}$.

\section{Materials and methods}

\subsection{Plant material}

For indirect method of micropropagation callus has been establish from the explants other than meristem like leaves, petiole and internodal parts either from mother plants or from in vitro sterile culture.

\subsection{Explants and surface sterilization}

Fully expanded fresh leaves $(1.5-2.5 \mathrm{~cm})$, petioles $(1 \mathrm{~cm})$ and internodal segments $(1 \mathrm{~cm})$ were excised from actively growing branches. They were washed under running tap water, followed by immersion in $0.5 \%(\mathrm{w} / \mathrm{v})$ Bavistin solution for $30 \mathrm{~min}$, and rinsed 3-4 times with sterile distilled water. Isolated explants were than washed with distilled water added with two to four drops of tween -20 a wetting agent. Finally it was sterilized with $0.1 \%$ solution of mercuric chloride solution for $4-5$ minutes followed by final repetitive rinsing with sterilized distilled water in the sterile zone of laminar air flow cabinet.

\subsection{Inoculation, callus induction and regeneration}

The MS basal media (Murashige and Skoog, 1962) ${ }^{12}$ was supplemented with different concentrations and combinations of growth regulators, $3 \%(\mathrm{w} / \mathrm{v})$ sucrose and $0.8 \%(\mathrm{w} / \mathrm{v})$ agar. The $\mathrm{pH}$ of the media was adjusted to 5.8 before autoclaving at $121^{\circ} \mathrm{C}$ for $15 \mathrm{~min}$. Isolated plant parts are sectioned and inoculated on medium having different auxins and cytokinin. For callus formation auxins 2, 4-D (2, 4-dichloro-phenoxyacetic acid) in the concentration of $0.5-3.0 \mathrm{mg} / \mathrm{l}$ and NAA $(0.5 \mathrm{mg} / \mathrm{l})$ were used alone and also with the combination of cytokinin $0.5 \mathrm{mg} / \mathrm{l} \mathrm{BAP}$ was tested.

All cultures were incubated at a temperature of $25 \pm 2{ }^{\circ} \mathrm{C}$ under 16 hour photoperiod with a light intensity of $30 \mu \mathrm{mol} \mathrm{m}-2 \mathrm{~s}^{-1}$ provided by cool white fluorescent tubes (40W, Bajaj India Ltd).

After 8 weeks of culture, calluses were transferred onto the regeneration media under light condition of different concentrations of cytokinins and auxins were tested on shoot regeneration.

\subsection{Rooting of in vitro induced shoots}

in vitro formed shoots were excised with an axillary bud and cultured for rooting. Different auxins (IAA, IBA, NAA and AC) were used for rooting.

\subsection{Acclimatization}

In vitro rooted plants were removed from rooting medium and washed to remove adhering gel and transferred to plastic cups containing a mixture of vermiculite and sand (1:1). The plantlets were covered with polythene bag in order to maintain high humidity and were placed in a shaded place.

\subsection{Statistical analysis}

Each experiment was repeated at least 3 times. The results were recorded at a regular interval of 4 week of culture and analyzed by analysis of variance using randomized block design method.

Means were compared using Duncan's new multiple ranges test $^{13}$.

\section{Results and discussion}

Callus initiation occurred from the cut surface of the explant within one week on auxin supplemented media. 2,4-D was the most effective auxin for callus induction among the other auxins tested. Addition of BAP $(0.5 \mathrm{mg} / \mathrm{l})$ in the medium containing 2, 4$D$ enhanced the callus induction response. In the study of callus induction from various plant resources, segment of leaves and internodes of the in vitro raised shoots are the most efficient plant part of Morus alba used for the development of callus compare to other parts. These initiating tissue are more reliable and suitable for the cloning of elite plants species. During the research it was observered that the medium supplemented with the auxin 2, 4-D either added alone or with NAA or BAP gives satisfactory response and the medium enriched with 2, 4-D (1.0 $\mathrm{mg} / \mathrm{l})$ and BAP $(0.5 \mathrm{mg} / \mathrm{l})$ proved the best and standardized for fastest callus development which was further utilized for the regeneration of plant of Morus alba. The maximum explants forming callus on this medium was $80 \%$ with the formation of dark green friable callus in the duration of 30 days (Table 1).

High concentrations of BAP inhibited callus formation from different explants. Pre-soaking of internodal explants in cytokinin has been demonstrated to be essential for callus initiation in Morus bombycis ${ }^{5}$. In contrast, our study indicates that the pretreatment of explants with BAP is not a prerequisite for callus initiation as earlier reported in $M$. alba $a^{6}$. Jain and Datta $(1992)^{5}$ used explants from in vitro raised shoots that were produced on an auxin rich medium. It is possible that auxin level has increased in the explants on an auxin supplemented medium and treatment of these explants with cytokinin compensates differences in endogenous cytokinin/auxin ratio. Leaf explants showed best callus forming ability, whereas petiole explants showed least callus initiation in the varieties investigated. Variation in callus forming ability of different explant types has been reported in $M$. $a l b a^{5}$.

Produced callus sub cultured on the freshly prepared regeneration medium having $1.0 \mathrm{mg} / \mathrm{I}(2,4-\mathrm{D})$ and $0.5 \mathrm{mg} / \mathrm{l}$ (BAP). The callus turned green after 3 subcultures on optimal callus induction medium. Shoot buds appeared on the surface of the calluses obtained from leaf upon their transfer to MS media supplemented with growth regulators after 2 weeks of culture. A similar effect of explant type on shoot forming capacity of callus cultures has been reported for $M$. alba ${ }^{5}$. In contrast, calluses derived from intermodal segments of $M$. indica was best for organogenesis ${ }^{7}$. The shoot buds developed into $2-3 \mathrm{~cm}$ long

Pharm \& Biosci J. 2020: 8(4); 42 
Dubey et al., Effect of Growth Regulators on Callus Culture and Regeneration of Morus alba

shoots after 4 weeks of culture. Cytokinin type and concentration had a significant effect on shoot differentiation. BAP was more effective than kinetin for shoot induction. Best shooting response in terms of percent of calluses forming shoots (90\%) and number of shoots formed per callus $(7.5 \pm 0.2)$ was obtained on a medium supplemented with $1 \mathrm{mg} / \mathrm{I}$ with 0.5 NAA (Table 2).

Table 1. Effect of growth regulators on callus induction of Morus alba

\begin{tabular}{|c|c|c|c|}
\hline MS+ GR (mg/l) & $\%$ Callus induction & No. of days & Morphology of Callus \\
\hline $0.52,4-D$ & 40.0 & 20 & Dark green \\
\hline $1.02,4-\mathrm{D}$ & 70.0 & 20 & Dark Green, compact \\
\hline $2.02,4-D$ & 50.0 & 30 & Dark Brown, compact \\
\hline $3.02,4-D$ & 40.0 & 30 & Brown compact \\
\hline $0.52,4-\mathrm{D}+0.5 \mathrm{BAP}$ & 60.0 & 30 & Green friable \\
\hline $1.02,4-D+0.5$ BAP & 80.0 & 30 & Dark green friable \\
\hline $2.02,4-\mathrm{D}+0.5 \mathrm{BAP}$ & 30.0 & 30 & Greenish yellow, compact \\
\hline $0.52,4-\mathrm{D}+0.5 \mathrm{NAA}$ & 70.0 & 20 & Whitish, green friable \\
\hline $1.02,4-\mathrm{D}+0.5 \mathrm{NAA}$ & 40.0 & 30 & Greenish brown, compact \\
\hline $2.02,4-\mathrm{D}+0.5 \mathrm{NAA}$ & 30.0 & 40 & Brownish green soft, compact \\
\hline
\end{tabular}

Table 2. Effect of growth regulators on shoot regeneration from callus of Morus alba

\begin{tabular}{lcccc}
\hline MS+ GR (mg/l) & $\begin{array}{c}\text { \%Shoot } \\
\text { regeneration }\end{array}$ & $\begin{array}{c}\text { No. of } \\
\text { culture days }\end{array}$ & $\begin{array}{c}\text { Mean no. of shoots } \\
\text { produced } \pm \text { SE }\end{array}$ & $\begin{array}{c}\text { Mean shoot } \\
\text { length (cm) } \pm \text { SE }\end{array}$ \\
\hline $\mathrm{MS}+0.5 \mathrm{BAP}$ & 40.0 & 30 & $2.8 \pm 0.5$ & $3.0 \pm 1.0$ \\
$\mathrm{MS}+0.5 \mathrm{KN}$ & 30.0 & 30 & $2.0 \pm 0.1$ & $2.7 \pm 0.14$. \\
$\mathrm{MS}+1.0 \mathrm{BAP}$ & 70.0 & 30 & $5.1 \pm 0.0$ & $6.5 \pm 0.5$ \\
$\mathrm{MS}+1.0 \mathrm{KN}$ & 40.0 & 30 & $3.0 \pm 0.11$ & $2.5 \pm 0.11$ \\
$\mathrm{MS}+0.5 \mathrm{BAP}+0.5 \mathrm{IBA}$ & 50.0 & 30 & $6.6 \pm 0.1$ & $5.8 \pm 0.8$ \\
$\mathrm{MS}+0.5 \mathrm{KN}+0.5 \mathrm{IBA}$ & 40.0 & 30 & $3.7 \pm 0.3$ & $4.5 \pm 0.9$ \\
$\mathrm{MS}+1.0 \mathrm{BAP}+0.5 \mathrm{NAA}$ & 90.0 & 20 & $7.5 \pm 0.2$ & $6.0 \pm 0.8$ \\
$M S+1.0 \mathrm{KN}+0.5 \mathrm{NAA}$ & 40.0 & 30 & $4.0 \pm 0.1$ & $3.0 \pm 0.1$ \\
$M S+2.0 \mathrm{BAP}+0.5 \mathrm{IAA}$ & 70.0 & 30 & $4.9 \pm 0.7$ & $5.0 \pm 0.7$ \\
$M S+2.0 \mathrm{KN}+0.5 \mathrm{IAA}$ & 40.0 & 30 & $3.6 \pm 0.1$ & $3.1 \pm 0.1$ \\
\hline
\end{tabular}

The superiority of BAP has also been previously reported in $M$. alba $^{14,15}, M$. indica ${ }^{7}$ and $M$. bombycis ${ }^{5}$. Addition of auxins inhibited the morphogenic response and increased callus proliferation The shoot forming ability of callus cultures of $M$. alba has also been reported to decrease with high concentrations of BAP $(2.0 \mathrm{mg} / \mathrm{I})$ in the medium ${ }^{15,5}$. Incorporation of NAA in media significantly enhanced the shoot formation response.

Regenerated shoots were excised and transferred to MS medium enriched with different auxins (AC, IAA, IBA, and NAA). AC was most effective additive, and the auxin IBA $(2.0 \mathrm{mg} / \mathrm{l})$ in terms of percent of shoots forming roots ( 80 to $70 \%$ ) within 20 days (1.5 $\mathrm{cm}$ ) (Table 3). IBA has also been reported to be favorable auxin for root formation in M. alba and M. bombycis ${ }^{5}$. Shoots were not able to develop roots on a medium that lacked auxins. Higher level of auxins encouraged callus formation from cut ends of the explants. Regenerated plants were hardened with a $80 \%$ success rate. On their transfer to the potting mixture (sand and vermiculite 1:1) $70 \%$ plants survived (Fig 1).

\section{Conclusions}


Dubey et al., Effect of Growth Regulators on Callus Culture and Regeneration of Morus alba

A simple, reproducible and efficient in vitro protocol for regenerating plants of $M$. alba has been developed from leaf explants. This procedure has four culture stages consisting of callus induction with the combination of high auxin and low cytokinin, proliferation and regeneration in the presence of high cytokinin, low auxin and finally a rooting stage with an additive

\section{Table 3. Effect of growth regulators on Root induction of Morus alba}

\begin{tabular}{lccc}
\hline MS+ GR (mg/l) & \%Root formation & No. of days & Mean Root length $(\mathbf{c m}) \pm$ SE \\
\hline$M S+20$ AC & 60.0 & 20 & $4.0 \pm 0.4$ \\
$M S 1 / 2+20$ AC & 80.0 & 20 & $7.0 \pm 0.6$ \\
$M S 1 / 2+0.5$ IBA & 60.0 & 20 & $5.3 \pm 0.8$ \\
$M S 1 / 2+1.0$ IBA & 50.0 & 20 & $3.5 \pm 0.0$ \\
$M S 1 / 2+2.0$ IBA & 70.0 & 20 & $6.5 \pm 0.6$ \\
$M S 1 / 2+0.5$ NAA & 50.0 & 20 & $3.8 \pm 0.2$ \\
$M S 1 / 2+1.0$ NAA & 40.5 & 30 & $2.5 \pm 0.7$ \\
$M S+2.0$ NAA & 60.0 & 30 & $5.0 \pm 0.1$ \\
$M S+0.5$ IAA & 30.0 & 20 & $4.0 \pm 0.2$ \\
$M S+1.0$ IAA & 30.0 & 30 & $2.0 \pm 0.2$ \\
\hline
\end{tabular}
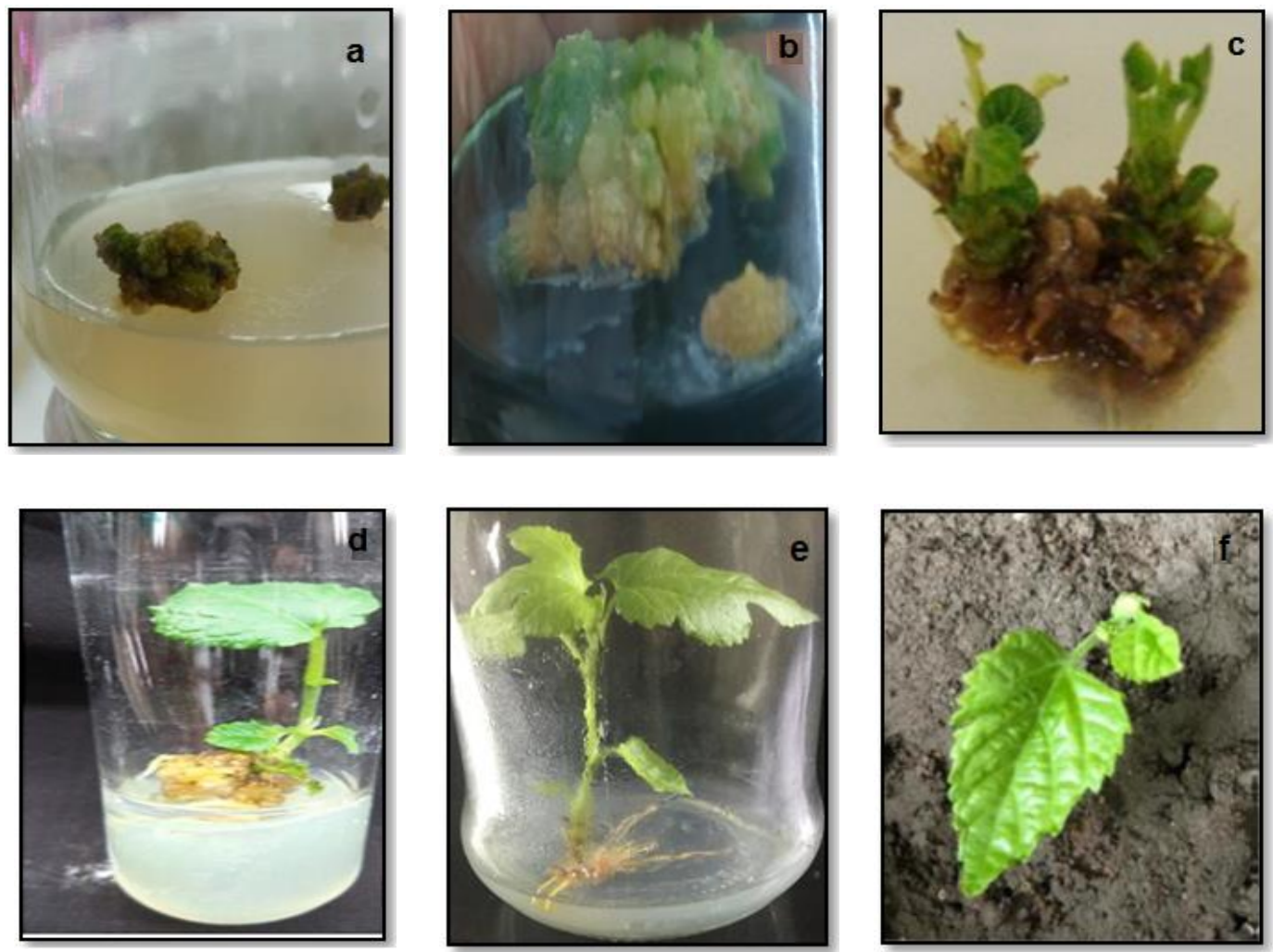

Fig 1: (a)- Callus formation on 1.0mg/l 2, 4 D media; (b)- Callus formation on 0.5 mg/l 2, 4 D +0.5 NAA media; (c) \& (d)- Shoot regeneration from callus on 1.0 BAP + 0.5 NAA media; (e)- Rooting formation in MS 1/2+20 mg/l AC media; (f)- Hardened plant of Morus alba 


\section{Abbreviations}

AC - activated Charcoal; 2,4-D - 2,4-dichlorophenoxyacetic acid; BAP - 6-benzylaminopurine; NAA - $\propto$ - napthaleneacetic acid; IBA - indole-3-butyric acid; MS - Murashige \& Skoog.

\section{Conflict of interest}

\section{None}

\section{Author's contributions}

VD, KWS and RKR performed the experimental work. SK drafted the manuscript, and all author approved the article for publication.

\section{References}

1. Wakhlu AK, Bhau BS. Tissue culture studies in mulberry - A review. Sericologia. 2000; 41: 1-20.

2. Dandin SB, Sengupta K. Mulberry cultivation as high bush and small tree in hilly regions. In: Dandin SB \&Sengupta K (eds) Genetic Resources of Mulberry Utilization (pp 3-4). Central Sericulture Research and Training Institute, Mysore, India, 1988.

3. Rajan MV, Dandin SB, Ramesh SR. Morus multicaulis, a potential exotic introduction for mulberry improvement programme in India. Sericologia. 1992; 32: 85-90.

4. Bhau BS. Tissue culture studies of some difficult-toroot temperate varieties of Morus alba (L.) and Morus multicaulis (PERR.). Ph.D. Thesis, Jammu University. Jammu, India, 1999.

5. Jain AK, Datta RK. Shoot organogenesis and plant regeneration mulberry (Morus bombycis Koidz.): Factors influencing morphogenetic potential in callus cultures. Plant Cell Tiss. Org. Cult. 1992; 29: 43-50.

6. Kathiravan K, Shajahan A, Ganapathi A. Regeneration of plantlets from hypocotyl derived callus of Morus alba. Israel J. Plant Sci. 1995; 43: 259-262.
7. Sahoo Y, Pattnaik SK, Chand PK. Plant regeneration from callus cultures of Morus indica $\mathrm{L}$. derived from seedlings and mature plants. Scientia Hort. 1997; 69: 85-98.

8. Vijayan K, Chajraborti SP, Roy BN. Regeneration of plantlets through callus culture in mulberry. Ind. J. Plant. Physiol. 1998; 3: 310-313.

9. Fotadar RK, Ahsan MQ, Dhar KL, Dhar A. Screening of mulberry varieties for rooting and induction of rooting by the use of growth regulators. Sericologia. 1990; 30: 347-361.

10. Detrez C, Sangwan RS, Sangwan-Norreel BS. Phenotypic and karyotypic status of Beta vulgaris plants regenerated from direct organogenesis in petiole culture. Theor. Appl. Genet. 1989; 77: 462468.

11. Tetu T, Sangwan RS \& Sangwan-Norreel BS. Hormonal control of organogenesis and somatic embryogenesis in Beta vulgaris callus. J. Exp. Biol. 1987; 38: 506-517.

12. Murashige T, Skoog F. A revised medium for rapid growth and bioassays with tobacco tissue cultures. Physiol. Plant. 1962; 15: 473-497.

13. Duncan DB. Multiple range and multiple F-tests. Biometrics. 1955; 11: 1-42.

14. Kathiravan K, Ganapathi A, Shajahan A. Adventitious shoot formation and plant regeneration from callus cultures of mulberry (Morus alba L.) Sericologia. 1997; 37: 727-733.

15. Narayan P, Chakraborty S, Rao GS. Regeneration of plantlets from the callus of stem segments of mature plants of Morus alba L. Proc. Ind. Nat. Sci. Acad. 1989; 55: 469-472. 